\title{
Clinical profile of cluster headaches in China - a clinic-based study
}

\author{
Zhao Dong, Hai Di, Wei Dai, Meiyan Pan, Zheng Li, Jingyao Liang, Mingjie Zhang, Zhibin Zhou, Ruozhuo Liu \\ and Shengyuan $\mathrm{Yu}^{*}$
}

\begin{abstract}
Background: The clinical profile of cluster headache in Chinese patients have not been fully studied.

Methods: The classification and clinical features of 120 consecutive patients with cluster headache (105 males, 15 females; mean age, $34.9 \pm 10.5$ years) visiting at International Headache Center from May 2010 to August 2012 were analyzed.

Results: Patients came from 16 different regions of China. Mean age at onset of cluster headache was $26.7 \pm 10.9$ years. Only 13 patients (10.8\%) had previously been diagnosed with cluster headache. Mean time to diagnosis from first symptoms was $8.2 \pm 7.1$ years (range, $0-35$ years). Chronic cluster headache was observed in only 9 patients (7.5\%). The most commonly reported location of cluster headache was temporal region (75.0\%), followed by retro-orbital region (68.3\%), forehead (32.5\%), vertex (32.5\%) and occipital (22.5\%). Lacrimation was the most consistently reported autonomic feature (72.5\%). During acute attacks, $60.0 \%$ of patients experienced nausea, and $41.7 \%$ experienced photophobia and 40.8\% experienced phonophobia. In addition, 38.3\% reported restless behavior and $45.8 \%$ reported that physical activity exacerbated the pain. None of patients experienced visual or other kinds of aura symptoms before cluster attacks. We found that $38.3 \%$ of patients had $<1$ cluster period and $35.8 \%$ for $1-2$ cluster periods per year with these periods occurring less frequently during the summer than during other seasons. Cluster duration was $1-2$ months in $32.5 \%$ of patients. During cluster periods, $73.3 \%$ of patients had 1-2 attacks per day, and 39.2\% experienced cluster attacks ranging in duration from $1 \mathrm{~h}$ to less than $2 \mathrm{~h}$. The duration of attacks were $1.5(1-2.25)$ hours for males and $1.5(1-3)$ for females respectively. The World Health Organization quality of life-8 questionnaire showed that cluster headache reduced life quality.

Conclusions: Compared to Western patients, Chinese patients showed a relatively low prevalence of chronic cluster headaches, pain sites mainly focused on areas distributed by the first division of the trigeminal nerve, a low frequency of restlessness and absent aura. These clinical features may be more common in Eastern populations, including mainland Chinese, Japanese and Taiwanese patients, than in Western patients.
\end{abstract}

Keywords: Cluster headache, Chinese, Features, Sense of restlessness

\section{Background}

Cluster headache $(\mathrm{CH})$ is an excruciating primary headache disorder, classified with similar conditions known as trigeminal autonomic cephalalgias [1]. Patients always describe the pain of a single attack as being worse than anything else they have experienced. Headaches are characterized by unilateral pain usually involving the orbital or periorbital region innervated by the first (ophthalmic)

\footnotetext{
*Correspondence: yusy1963@126.com

International Headache Center, Department of Neurology, Chinese PLA General Hospital, Fuxing Road 28 Haidian District, Beijing 100853, China
}

division of the trigeminal nerve and are accompanied by ipsilateral autonomic features, including lacrimation, conjunctival injection, nasal congestion and/or rhinorrhea, ptosis and/or miosis, and periorbital edema. $\mathrm{CH}$ show male predominance and a periodic occurrence and circadian rhythm of cluster attacks [2-4]. Diagnostic criteria for $\mathrm{CH}$ have been established by the International Headache Society [1]. Knowledge and understanding of $\mathrm{CH}$ derive primarily from studies in Western populations [5-13]. The clinical characteristics of $\mathrm{CH}$ in other regions of the world, including Asia, however, are not well understood [14,15]. 
To our knowledge, little is known about the characteristics of $\mathrm{CH}$ in patients from the Chinese mainland. We have characterized the clinical profile of $\mathrm{CH}$ in China by surveying $\mathrm{CH}$ patients registered at a headache clinic in Beijing, China.

\section{Methods}

The study population consisted of patients diagnosed with $\mathrm{CH}$, as defined by the second edition of the International Classification of Headache Disorders (ICHD-II) [1], on first consultation from May 2010 to August 2012 at the International Headache Center of Chinese PLA General Hospital in Beijing, China, accredited by International Headache Society. For each patient, a detailed clinic questionnaire for headache disorders was completed by a certified neurologist in headache center during the initial consultation and the diagnosis was made by at least two headache specialists together. Magnetic resonance imaging of the head/brain was applied to rule out symptomatic origin for every headache patient.

A detailed database for each headache patient was set up including clinical information such as age, gender, course of disease, pain intensity, possible trigger factors, autonomic features, additional features (e.g. nausea, vomiting, photophobia, phonophobia, behaviors during attacks, and aggravation after activity), frequency and duration of clusters, frequency and duration of attack onset, family history of headache, history of smoking and drinking, and quality of life. Maximum pain intensity was estimated using a visual analogue scale (VAS). The study protocol was approved by the ethics committee of the Chinese PLA General Hospital, Beijing.

All measurements were reported as mean $\pm \mathrm{SD}$. Categorical variables were compared using the chi-square test, and continuous variables were compared using Student's $t$-test or one-way analysis of variance (ANOVA). SPSS for

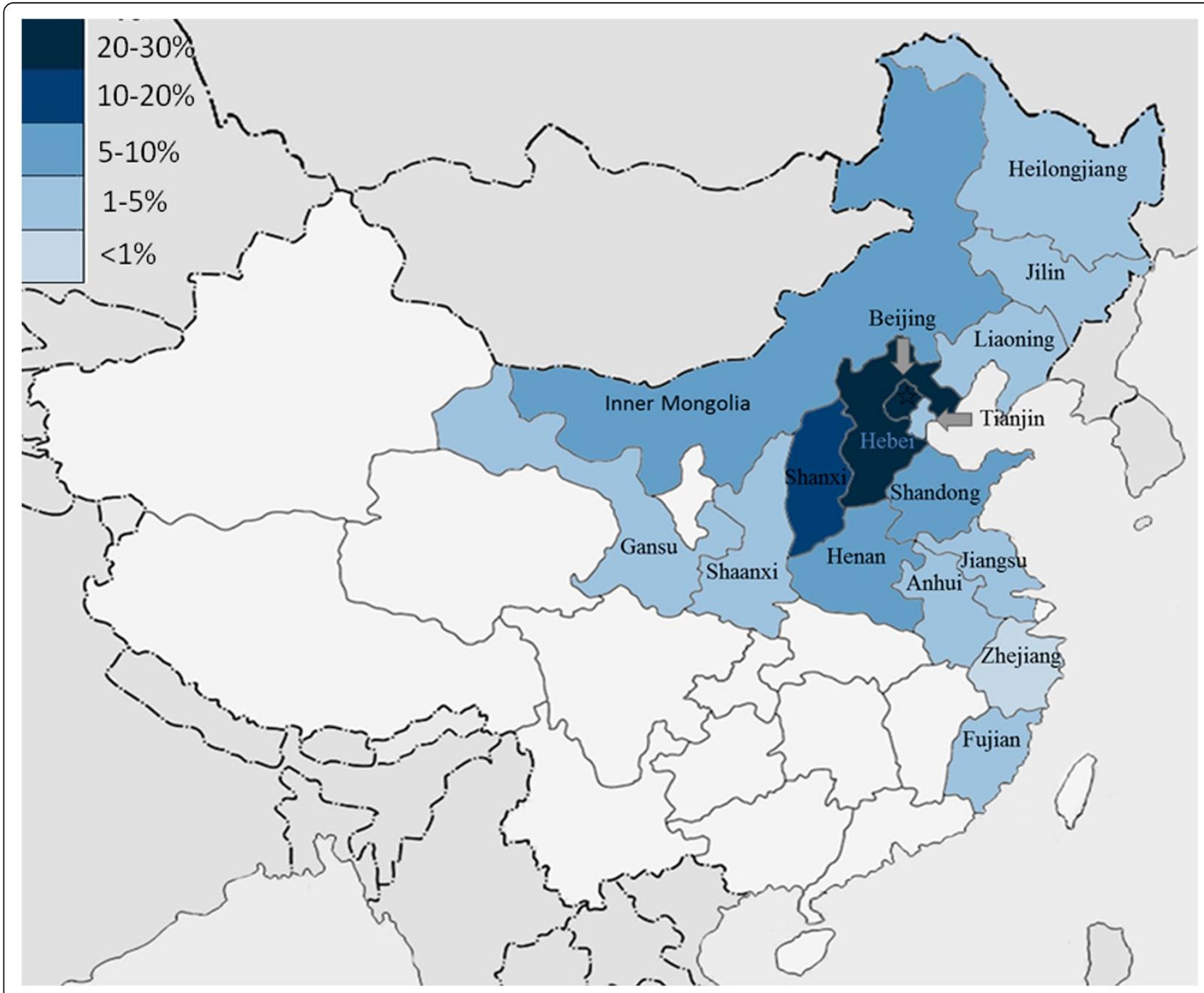

Figure 1 Regional distribution of cluster headache patients in the current study $(\mathbf{n}=\mathbf{1 2 0})$. Patients came from 16 regions of China. Colors from dark to light indicate different proportion of headache patients from higher to lower (5 levels: 20-30\%, 10-20\%, 5-10\%, 1-5\%, and <1\%). 
Table 1 Demographics of subjects with cluster headache

\begin{tabular}{|c|c|c|c|c|}
\hline Patient characteristics & Total $\mathrm{N}=120$ & Males $n=105$ & Females $n=15$ & P-value \\
\hline \multicolumn{5}{|l|}{ Type of cluster headache } \\
\hline Episodic & 111 & 97 & 14 & 1.00 \\
\hline Chronic & 9 & 8 & 1 & \\
\hline Age in years (mean $\pm S D$ ) & $34.9 \pm 10.5$ & $34.7 \pm 10.6$ & $36.5 \pm 9.7$ & \\
\hline Age at onset in years (mean $\pm S D$ ) & $26.7 \pm 10.9$ & $26.6 \pm 10.8$ & $28.0 \pm 11.4$ & 0.652 \\
\hline Pain intensity (VAS) & $8.9 \pm 1.4$ & $8.9 \pm 1.4$ & $8.6 \pm 1.6$ & 0.454 \\
\hline Family history of Cluster headache & 8 & & & \\
\hline Mother & 2 & & & \\
\hline Father & 4 & & & \\
\hline Others & 2 & & & \\
\hline
\end{tabular}

*The ratio of males to female was 7:1.

Windows, Version 20.0, was used for statistical analyses with the significance level set at $P=0.05$.

\section{Results}

\section{Area distribution of patients}

Patients came from 16 regions of China (Figure 1). Most of them lived in North and Eastern China including Hebei (29, 24.2\%), Beijing (25, 20.8\%), Shanxi (15, 12.5\%), Inner Mongolia (8, 6.7\%), Henan (8, 6.7\%), Shandong (10, 8.3\%). Other areas consist of Anhui (4, 3.3\%), Gansu (3, 2.5\%), Heilongjiang (2, 1.7\%), Jilin (3, 2.5\%), Jiangsu (3, 2.5\%), Fujian (2, 1.7\%), Liaoning (3, 2.5\%), Shaanxi (2, 1.7\%), Tianjin $(2,1.7 \%)$ and Zhejiang $(1,0.8 \%)$.

\section{Study population}

Of the 120 patients enrolled in this study, 105 were male and 15 were female, giving a male-to-female (M: F) ratio of 7:1; of these, 111 (92.5\%) had episodic $\mathrm{CH}(\mathrm{ECH})$ and 9 (7.5\%) had chronic $\mathrm{CH}(\mathrm{CCH})$. Mean age at first consultation at our clinic was $34.9 \pm 10.5$ years (males, $34.7 \pm$ 10.6 years vs. females, $36.5 \pm 9.7$ years). Mean age at onset was $26.7 \pm 10.9$ years and was similar in males and females $(26.6 \pm 10.8$ years vs. $28.0 \pm 11.4$ years, $\mathrm{P}=0.652)$. The mean VAS of all patients was $8.9 \pm 1.4,8.9 \pm 1.4$ in males and $8.6 \pm 1.6$ in females $(\mathrm{P}=0.454)$ (Table 1). One $\mathrm{CH}$ male patient has already suffered trigeminal neuralgia. Two patients $(1.6 \%, 2 \mathrm{M})$ also had migraine headaches and five patients $(4.2 \%, 3 \mathrm{M}, 2 \mathrm{~F})$ had tension-type headaches. Eight patients $(6.7 \%)$ gave a family history of $\mathrm{CH}$ (diagnosed with identified and classic clinical features), including mother (two patients), father (four patients) and other relatives (two patients). Peak age at onset was 20-29 years for both males and females (Figure 2).

\section{History of smoking and drinking}

Sixty-six (55\%) CH patients had a positive history of tobacco exposure including 59 (49.2\%) current smokers and 7 (5.8\%) ex-smokers. Other $45 \%(54 / 120)$ sufferers stated they had never smoked prior to cluster headache onset. Almost 49.2\% (59/120) of the surveyed patients stated they drank alcohol and 5\% (6/120) have stopped drinking.

\section{Sites and laterality of headache}

The most commonly reported location of $\mathrm{CH}$ was temporal region $(75.0 \%)$, followed by retro-orbital region

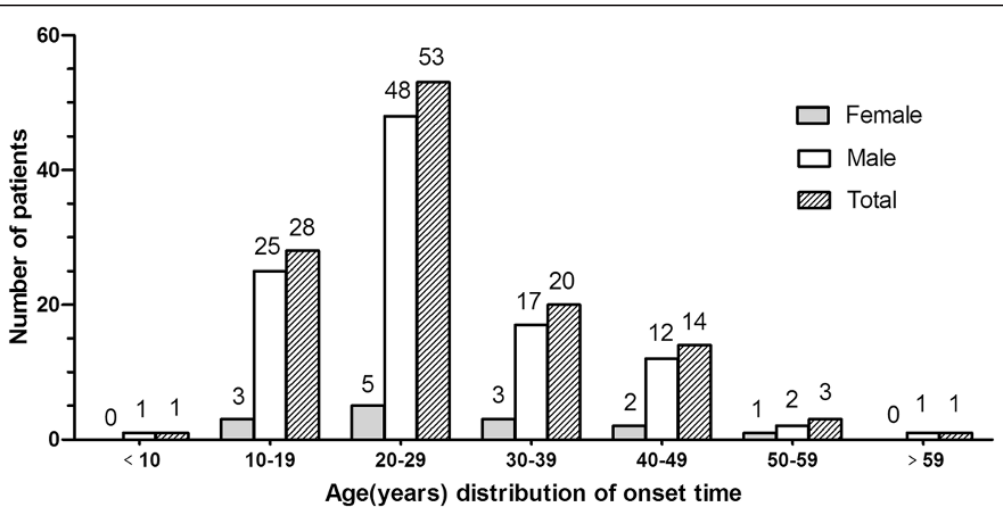

Figure 2 Age distribution at onset for cluster headache. The peak age at onset for male and female were both in the $2^{\text {nd }}$ decade of life. 
Table 2 The locations and laterality of pain in $\mathrm{CH}$ patients

\begin{tabular}{|c|c|c|c|c|}
\hline & Total $(\mathrm{N}=120)$ & Males $(n=105)$ & Females $(n=15)$ & P-value \\
\hline \multicolumn{5}{|l|}{ Sites of pain } \\
\hline Temporal & $90(75.0)$ & $78(74.3)$ & $12(80.0)$ & 0.759 \\
\hline Retro-orbital & $82(68.3)$ & $71(67.6)$ & $11(73.3)$ & 0.773 \\
\hline Forehead & $39(32.5)$ & $36(34.3)$ & $3(20.0)$ & 0.381 \\
\hline Vertex & $39(32.5)$ & $32(30.5)$ & $7(46.7)$ & 0.244 \\
\hline Occipital & $27(22.5)$ & $24(22.9)$ & $3(20.0)$ & 1.00 \\
\hline Neck & $5(4.2)$ & $5(4.8)$ & 0 & 1.00 \\
\hline Teeth & $5(4.2)$ & $5(4.8)$ & 0 & 1.00 \\
\hline Ear & $5(4.2)$ & $5(4.8)$ & 0 & 1.00 \\
\hline Cheek & $3(2.5)$ & $3(2.9)$ & 0 & 1.00 \\
\hline Nose & $2(1.7)$ & $2(1.9)$ & 0 & 1.00 \\
\hline \multicolumn{5}{|l|}{ Laterality of pain } \\
\hline Right-side only & $62(51.7)$ & $55(52.4)$ & $7(46.7)$ & 0.785 \\
\hline Left-side only & $43(35.8)$ & $40(38.1)$ & $3(20.0)$ & 0.251 \\
\hline Predominant right-side & $5(4.2)$ & $4(3.8)$ & $1(6.7)$ & 0.493 \\
\hline Predominant left-side & $4(3.3)$ & $2(1.9)$ & $2(13.3)$ & 0.076 \\
\hline Changing sides & $6(5.0)$ & $4(3.8)$ & $2(13.3)$ & 0.163 \\
\hline
\end{tabular}

Results are reported as number of patients (percent).

(68.3\%), forehead (32.5\%), vertex (32.5\%) and occipital $(22.5 \%)$ (Table 2). Other sites of pain included neck (4.2\%), teeth (4.2\%), ear (4.2\%), cheek (2.5\%) and nose $(1.7 \%)$. Strictly unilateral headache was most frequently reported (right side $51.7 \%$, left side $36.7 \%$ ), followed by predominantly right side (4.2\%) and left side (3.3\%).
However, six (5.0\%) patients also experienced equal attacks on shifting sides among different attacks.

Cranial autonomic and additional features in patients with $\mathrm{CH}$ Lacrimation $(72.5 \%)$ was the most consistently reported autonomic feature, followed by conjunctival injection

Table 3 Cranial autonomic and additional features in patients with cluster headache

\begin{tabular}{|c|c|c|c|c|}
\hline & Total $(\mathrm{N}=120)$ & Males $(\mathrm{N}=105)$ & Females $(N=15)$ & P-value \\
\hline \multicolumn{5}{|l|}{ Autonomic features } \\
\hline Lacrimation & $87(72.5) ※$ & 77(73.3) & $10(66.7)$ & 0.553 \\
\hline Conjunctival injection & $76(63.3)$ & $67(63.8)$ & $9(60.0)$ & 0.781 \\
\hline Rhinorrhea & $40(33.3) ※$ & $38(36.2)$ & $2(13.3)$ & 0.140 \\
\hline Nasal congestion & $39(32.5)$ & $37(35.2)$ & $2(13.3)$ & 0.139 \\
\hline Ptosis/miosis & $20(16.7)$ & $17(16.2)$ & $3(20.0)$ & 0.714 \\
\hline Facial sweating & 22(18.3)\# & 20(19.0) & $2(13.3)$ & 0.736 \\
\hline Blepharoedema & $28(23.3)$ & 23(21.9) & $5(33.3)$ & 0.338 \\
\hline \multicolumn{5}{|l|}{ Additional features } \\
\hline Nausea & $72(60.0)$ & $64(61.0)$ & $8(53.3)$ & 0.585 \\
\hline Vomiting & $40(33.3)$ & $36(34.3)$ & $4(26.7)$ & 0.771 \\
\hline Photophobia & $50(41.7)$ & $43(41.0)$ & $7(46.7)$ & 0.782 \\
\hline Phonophobia & $49(40.8)$ & $42(40.0)$ & $7(46.7)$ & 0.780 \\
\hline Sense of restlessness and agitation & $46(38.3)$ & $40(33.3)$ & $6(40.0)$ & 1.00 \\
\hline Aggravation by physical activities & $55(45.8)$ & $46(43.8)$ & $9(60.0)$ & 0.277 \\
\hline Aura & 0 & 0 & 0 & \\
\hline
\end{tabular}

Results are reported as number of patients (percent). ※ The symptom occurred bilaterally in two patients. \# The symptom occurred bilaterally in three patients. 
Table 4 Frequency and duration of clusters and onset of attacks

\begin{tabular}{|c|c|c|c|}
\hline & Total $(\mathrm{N}=120)$ & Males $(n=105)$ & Females $(n=15)$ \\
\hline \multicolumn{4}{|l|}{ Frequency of clusters } \\
\hline More than 2 times/yr & $9(7.5)$ & $7(6.7)$ & $2(13.3)$ \\
\hline $1-2$ times/yr & $43(35.8)$ & $36(34.3)$ & $7(46.7)$ \\
\hline Less than 1 time/yr & $46(38.3)$ & $42(40.0)$ & $4(26.7)$ \\
\hline First experience of cluster & $14(11.7)$ & $13(12.4)$ & $1(6.7)$ \\
\hline Irregular & $8(6.7)$ & $7(6.7)$ & $1(6.7)$ \\
\hline \multicolumn{4}{|l|}{ Duration of clusters } \\
\hline Less than 2 weeks & $17(14.2)$ & $14(13.3)$ & $3(20.0)$ \\
\hline From 2 weeks to less than 1 month & $34(28.3)$ & $27(25.7)$ & $7(46.7)$ \\
\hline From 1 to 2 months & $39(32.5)$ & $36(34.3)$ & $3(20.0)$ \\
\hline More than 2 months & $8(6.7)$ & $8(7.6)$ & 0 \\
\hline First experience of cluster & $14(11.7)$ & $13(12.4)$ & $1(6.7)$ \\
\hline Irregular & $8(6.7)$ & $7(6.7)$ & $1(6.7)$ \\
\hline \multicolumn{4}{|l|}{ Frequency of onset of attacks } \\
\hline More than 2 times/day & $16(13.3)$ & $12(11.4)$ & $4(26.7)$ \\
\hline 1 to 2 times/day & $88(73.3)$ & $81(77.1)$ & $7(46.7)$ \\
\hline Less than 1 time/day & $16(13.3)$ & $12(11.4)$ & $4(26.7)$ \\
\hline \multicolumn{4}{|l|}{ Duration of onset of attacks } \\
\hline Less than $1 \mathrm{~h}$ & $21(17.5)$ & $18(17.1)$ & $3(20.0)$ \\
\hline From $1 \mathrm{~h}$ to less than $2 \mathrm{~h}$ & $47(39.2)$ & $42(40.0)$ & $5(33.3)$ \\
\hline From $2 \mathrm{~h}$ to $3 \mathrm{~h}$ & $41(34.2)$ & $36(34.3)$ & $5(33.3)$ \\
\hline More than $3 \mathrm{~h}$ & $11(9.2)$ & $9(8.6)$ & $2(13.3)$ \\
\hline
\end{tabular}

Results are reported as number of patients (percent).

(63.3\%), rhinorrhea (33.3\%), nasal congestion (32.5\%), and less commonly, blepharoedema (23.3\%), facial sweating (18.3\%), Ptosis/miosis (16.7\%) (Table 3). Although cranial autonomic symptoms (CAS) of $\mathrm{CH}$ commonly occurred unilaterally, bilateral CAS including lacrimation $(2 / 87)$, rhinorrhea $(2 / 40)$, and facial sweating $(3 / 22)$ were also observed in our cohort. During acute attacks, $60.0 \%$ of individuals experienced nausea, $41.7 \%$ reported photophobia, and $40.8 \%$ experienced phonophobia. In addition, 38.3\% of patients experienced restless behavior, and $45.8 \%$ reported that physical activity exacerbated their pain. None of patients experienced visual or other kinds of aura symptoms before cluster attacks. There was no statistically significant difference in any of the clinical characteristics between male and female patient (Tables 2 and 3).

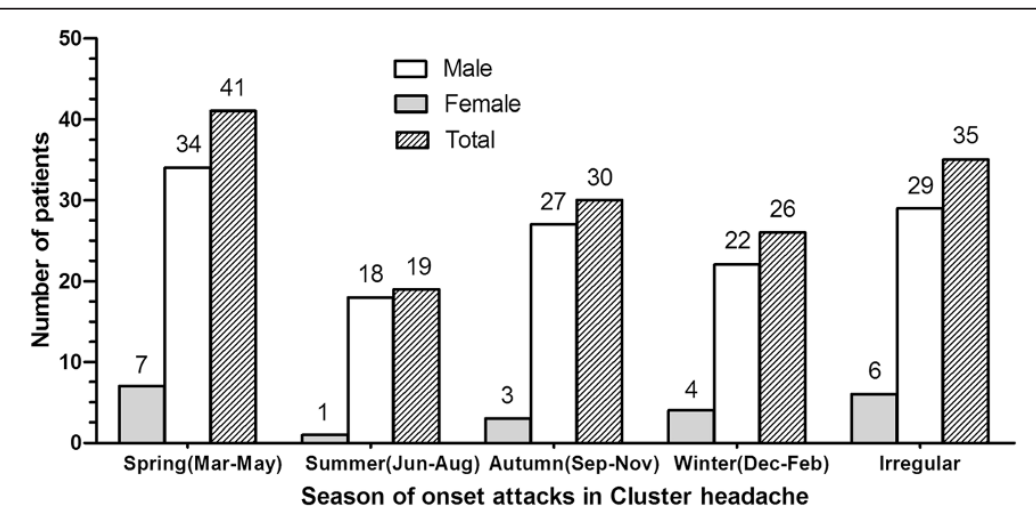

Figure 3 Season of onset attacks in cluster headache. A seasonal propensity of bout onset occurred mostly in spring and less frequent during the summer months. 


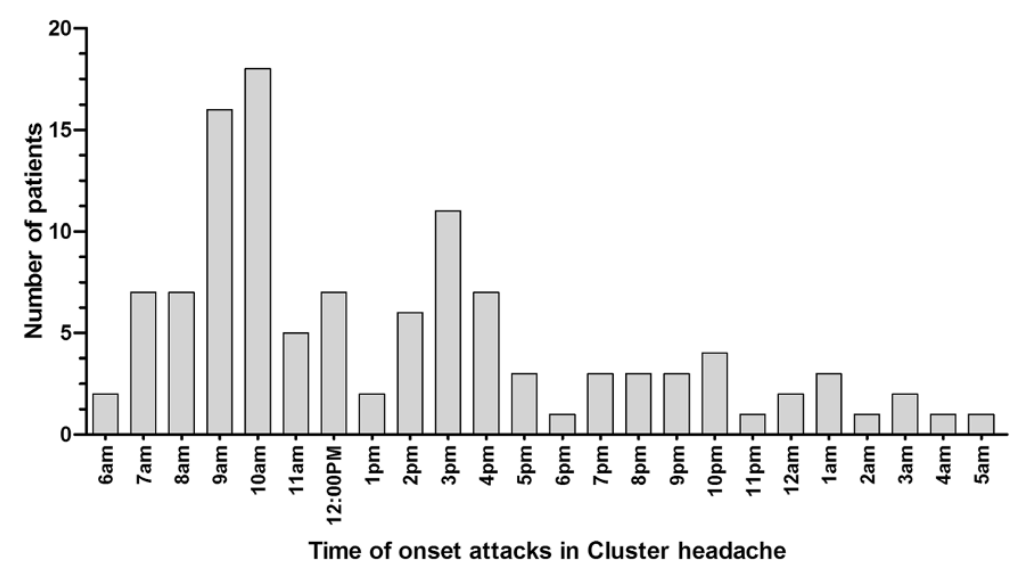

Figure 4 Time of onset attacks in cluster headache. Headaches occurred more commonly from 7 am to 10 am and from 2 pm to 4 pm.

\section{Periodicity of $\mathrm{CH}$}

We found that $38.3 \%$ of patients had $<1$ cluster period and $35.8 \%$ for $1-2$ cluster periods per year respectively. Only nine $(7.5 \%)$ had $>2$ cluster periods per year and $11.7 \%$ of patients have the first experience of cluster (Table 4). Almost $70.8 \%$ of individuals (85 patients) commented on a seasonal propensity of bout onset. This occurred mostly in spring (41/120, 34.2\%). However, these periods were less frequent during the summer months $(19 / 120,15.8 \%)$ than during other two seasons including autumn $(30 / 120,25.0 \%)$ and winter $(26 / 120$, $21.7 \%$ ) (Figure 3). The duration of cluster attacks were 1-2 months in $32.5 \%$ of patients, 2 weeks to less than 1 month in $28.3 \%$, less than 2 weeks in $14.2 \%$ and more than 2 months in $6.7 \%$ (Table 4).

Attacks occurred 1-2 times per day in $73.3 \%$ of patients, $>2$ times and $<1$ time per day both in $13.3 \%$ (Table 4 ).

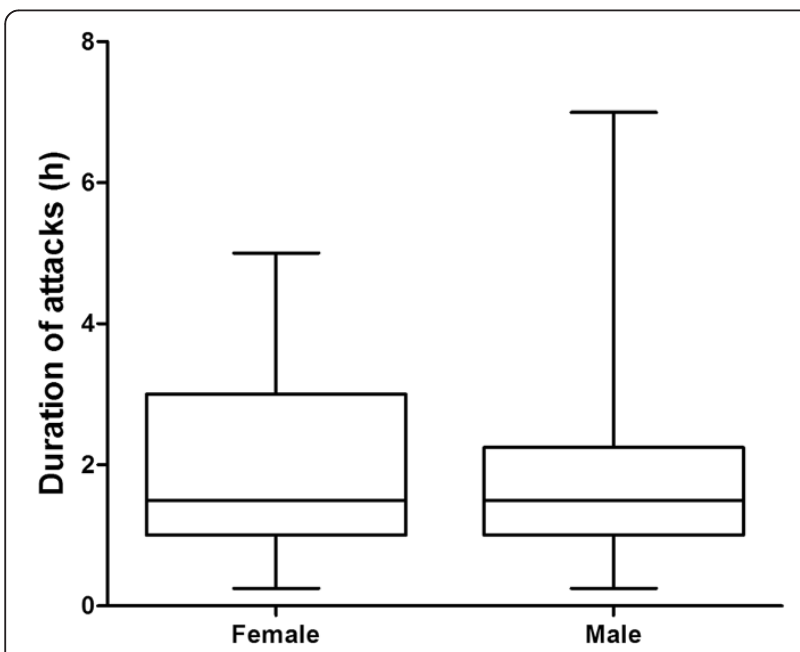

Figure 5 Duration of attacks in cluster headache. The duration of attacks were 1.5 (1-2.25) hours for males and 1.5 (1-3) for females respectively $(P=0.923)$.
Eighty-one (67.5\%) patients reported that their headaches occurred at a fixed time, more commonly from 7 am to $10 \mathrm{am}(40 \%, 48 / 120)$ and from $2 \mathrm{pm}$ to $4 \mathrm{pm}(20 \%, 24 /$ 120) (Figure 4). There are also 39 patients (32.5\%) who complained irregular headache attacks per day. We found that cluster attacks ranged in duration from $1 \mathrm{~h}$ to less than $2 \mathrm{~h}$ in $39.2 \%$ and from $2 \mathrm{~h}$ to $3 \mathrm{~h}$ in $34.2 \%$ of patients. Other $17.5 \%$ comment on the attack duration less than $1 \mathrm{~h}$ and $9.2 \%$ more than $3 \mathrm{~h}$ (Table 4). The duration of attacks were 1.5 (1-2.25) hours for males and 1.5 (1-3) for females respectively $(\mathrm{P}=0.923)$ (Figure 5$)$.

\section{Possible trigger factors}

Thirty-three of 59 (55.9\%) patients who had consumed alcohol reported headaches after alcohol consumption. Thirty-one $(25.8 \%)$ patients felt that weather or temperature changes triggered their headache. Twenty-six (21.7\%) patients experienced a headache attack when they had insufficient sleep and sixteen $(13.3 \%)$ patients aggravated after fatigue. Fourteen (11.7\%) patients complained of headaches after stress or labile mood. Finally, 4 patients reported that some special substances could induce headache attack ( 2 for cayenne pepper, 1 for gourmet power and 1 for stimulatory odour).

\section{Quality of life for $\mathrm{CH}$ patients}

$\mathrm{CH}$ had a negative impact on Quality of life (QoL) (Table 5). Average scores about the eight items of WHOQoL-8 in people with $\mathrm{CH}$ including life quality, health level, daily life ability, satisfied with yourself, interpersonal relationship, habitation condition, daily life energy and payment ability were $2.38 \pm 0.81,2.08 \pm$ $0.84, \quad 2.68 \pm 0.65,2.57 \pm 0.64,2.85 \pm 0.58,2.73 \pm 0.58$, $2.09 \pm 0.77$ and $2.10 \pm 0.60$, respectively. It seems that the scores were lower than the data of migraine from a nationwide population-based headache survey in the mainland of China (Table 5) [16]. 
Table 5 World Health Organization quality of life-8 mean scores (SD) for cluster headache

\begin{tabular}{lcc}
\hline & $\begin{array}{l}\text { Cluster headache } \\
(\mathbf{N}=\mathbf{1 2 0})\end{array}$ & $\begin{array}{l}\text { Migraine } \\
\text { (N = 464) [16] }\end{array}$ \\
\hline Life quality & $2.38(0.81)$ & $3.22(0.67)$ \\
Health level & $2.08(0.84)$ & $2.98(0.83)$ \\
Daily life ability & $2.68(0.65)$ & $3.35(0.78)$ \\
Satisfied with yourself & $2.57(0.64)$ & $3.45(0.80)$ \\
Interpersonal relationship & $2.85(0.58)$ & $3.76(0.68)$ \\
Habitation condition & $2.73(0.58)$ & $3.34(0.84)$ \\
Daily life energy & $2.09(0.77)$ & $3.03(0.72)$ \\
Payment ability & $2.10(0.60)$ & $2.60(0.66)$ \\
\hline
\end{tabular}

04 of each item represents 5 grades of living quality from good to bad.

\section{Time delay for correct diagnosis}

Only 13 patients (10.8\%) had previously been diagnosed with $\mathrm{CH}$. Mean time to diagnosis from first symptoms was $8.2 \pm 7.1$ years (range, $0-35$ years). In $40 \%$ (48/120) of the $\mathrm{CH}$ patients, it took 10 years $(14.2 \%)$ or longer $(25.8 \%)$ to receive a correct diagnosis (Table 6). Only the minority of patients $(10.8 \%)$ had a proper diagnosis of cluster headache in less than 1 year from symptom onset.

\section{Discussion}

To our knowledge, this study is the first survey of a clinicbased sample of patients with $\mathrm{CH}$ in mainland China. Most clinical characteristics of $\mathrm{CH}$ reported in this study are consistent with other studies from Western and Eastern regions in the world, which included gender dominance for male [4-15,17-22], similar age at onset [5-7,9,13-15,18,19], temporal or retro-orbital regions as common sites of pain [5,7,13-15], lacrimation as the most frequent autonomic feature [5,7,13-15], high frequencies of migrainous features,

\section{Table 6 Time delay for correct diagnosis of cluster} headache

\begin{tabular}{lc}
\hline Time delay to diagnosis & $\mathbf{N}(\%)$ \\
\hline Less than 1 year & $13(10.8)$ \\
1 year & $2(1.7)$ \\
2 years & $10(8.3)$ \\
3 years & $10(8.3)$ \\
4 years & $10(8.3)$ \\
5 years & $10(8.3)$ \\
6 years & $6(5.0)$ \\
7 years & $4(3.3)$ \\
9 years & $5(4.2)$ \\
10 years & $2(1.7)$ \\
More than 10 years & $17(14.2)$ \\
\hline
\end{tabular}

Results are reported as number of patients (percent). low frequency of positive family history and seasonal propensity in spring and autumn (Table 7). Yet, it is also worth noting some discrepancies between the current and previous results.

In current study the $\mathrm{CH}$ was much more prevalent in men than in women, with an M: F ratio of 7:1. This data was similar to findings in Taiwan (6.4: 1) [14], but a little higher than other reported M: F ratios ranging from 1.3:1 to $3.8: 1[5-7,9,13,15]$. Manzoni $[20,21]$ have observed a time-related decrease in $\mathrm{CH}$ male predominance over the years and speculated that lifestyle may play an important role in the development of $\mathrm{CH}$. Therefore, it may be conceivable that people from mainland China and Taiwan have similar M: F ratio due to their approximation of the lifestyle and cultural factors.

Of our 120 patients, only 9 (7.5\%) had $\mathrm{CCH}$. Other studies in Asian subjects have also reported a low prevalence of $\mathrm{CCH}(0-3.5 \%)$ [14,15]. This ratio is relatively much higher, however, in Western populations, in which $16.7-31.1 \%$ of patients with $\mathrm{CH}$ have been diagnosed with $\mathrm{CCH}[5-7,9]$. The lower prevalence of $\mathrm{CCH}$ in Asian patients may be due to racial, lifestyle or cultural factors.

Temporal or retro-orbital regions were predominant sites of pain in $\mathrm{CH}$ patients, under the distribution of the first division of the trigeminal nerve (Table 7). Other areas such as upper teeth, jaw and maxilla were also very common in Western populations $[5,7,13,23]$. However, the pain of $\mathrm{CH}$ patients in current study was mainly focused on areas distributed by the first division of the trigeminal nerve and rarely on sites dominated by the second and third division of the trigeminal nerve (Table 2). This clinical feature was also very common in other Eastern patients, including Japanese and Taiwanese patients (Table 7).

Aura phenomena, similar to those experienced during migraine including visual and sensory phenomena, have been found to precede attacks in $5.9 \%$ to $21 \%$ of Western $\mathrm{CH}$ patients (Table 7) [5,6,13,23-25], which is the same prevalence of aura in migraine sufferers. This symptom appears to occur in both male and female patients with $\mathrm{CH}$ and in both chronic and episodic $\mathrm{CH}$. None of our patients, however, were found to experience auras before cluster attacks. Similarly, only $1 \%$ of patients from Taiwan experienced aura [14]. The difference between Western and Eastern $\mathrm{CH}$ suffers may be also due to racial and genetic factors.

Studies in Western patients showed that $67.9 \%$ to $99.2 \%$ experience a sense of restlessness and agitation during an attack $[5-7,13]$. In contrast, we found that only $38.3 \%$ of our $\mathrm{CH}$ patients experienced restless and agitation. This finding is in agreement with results in other Asian populations, in that $51 \%$ of patients from Taiwan [14] and 69.8\% of patients from Japan [15]. This discrepancy between 
Table 7 Clinical characteristics of $\mathrm{CH}$ from different regions in the world

\begin{tabular}{|c|c|c|c|c|c|c|c|c|}
\hline & UK [5] 2002 & Germany [6] 2006 & Germany [7] 2012 & $\begin{array}{l}\text { Italy [9] } \\
2005\end{array}$ & USA [13] 2012 & Japan [15] 2011 & Taiwan [14] 2004 & Mainland China \\
\hline M:F Ratio & $2.5: 1$ & $3.5: 1$ & $3.4: 1$ & $1.3: 1$ & $2.6: 1$ & 3.8: 1 & 6.4: 1 & $7: 1$ \\
\hline $\mathrm{CCH}(\%)$ & $21 \%$ & $16.7 \%$ & $31.1 \%$ & $19 \%$ & - & $3.5 \%$ & 0 & $7.5 \%$ \\
\hline $\begin{array}{l}\text { Mean age at onset } \\
\text { (yrs) }\end{array}$ & $28.4(\mathrm{ECH}) 37(\mathrm{CCH})$ & - & 31.6 & 35.7 & $21-30 *$ & 31.0 & 26.9 & 26.7 \\
\hline Family history of $\mathrm{CH}$ & $5 \%$ & - & - & - & $18 \%$ & - & $5.8 \%$ & $6.7 \%$ \\
\hline $\begin{array}{l}\text { Common sites of } \\
\text { pain }\end{array}$ & $\begin{array}{l}\text { Retro-orbital, } \\
\text { temporal, upperteeth }\end{array}$ & - & $\begin{array}{l}\text { Peri-orbital, occipital, } \\
\text { orofacial }\end{array}$ & - & $\begin{array}{l}\text { Retro-orbital, } \\
\text { upper teeth, jaw }\end{array}$ & $\begin{array}{l}\text { Retro-orbital, } \\
\text { temporal, occipital }\end{array}$ & $\begin{array}{l}\text { Temporal, retro- } \\
\text { orbital, occipital }\end{array}$ & $\begin{array}{l}\text { Temporal, retro-orbital, } \\
\text { forehead }\end{array}$ \\
\hline $\begin{array}{l}\text { Predominant } \\
\text { laterality }\end{array}$ & Right & - & - & - & Right & Right & Right & Right \\
\hline $\begin{array}{l}\text { Most cranial } \\
\text { autonomic features }\end{array}$ & Lacrimation (91\%) & - & $\begin{array}{l}\text { Conjunctival injection } \\
\text { and/or lacrimation }\end{array}$ & - & Lacrimation (91\%) & Lacrimation (66.3\%) & Lacrimation (83\%) & Lacrimation (72.5\%) \\
\hline $\begin{array}{l}\text { Most additional } \\
\text { features }\end{array}$ & Photophobia (56\%) & $\begin{array}{l}\text { Photophobia/ } \\
\text { Phonophobia (61.2\%) }\end{array}$ & $\begin{array}{l}\text { Photophobia/ } \\
\text { Phonophobia (73.2\%) }\end{array}$ & - & $\begin{array}{l}\text { Photophobia } \\
(48 \%)\end{array}$ & Nausea (39.5\%) & Phonophobia (58\%) & Nausea (60.0)\% \\
\hline $\begin{array}{l}\text { Sense of agitation or } \\
\text { restlessness }\end{array}$ & $93 \%$ & $67.9 \%$ & $83 \%$ & - & $99.2 \%$ & $69.8 \%$ & $51 \%$ & $38.3 \%$ \\
\hline Aura & $14 \%$ & $23 \%$ & - & - & $21 \%$ & - & $1 \%$ & 0 \\
\hline $\begin{array}{l}\text { Most common } \\
\text { duration of attacks }\end{array}$ & $72-159 \mathrm{~min}$ & $45-180 \min (67.9 \%)$ & $98 \pm 75$ & - & - & $\begin{array}{l}\text { From } 1 \mathrm{~h} \text { to less } \\
\text { than } 2 \mathrm{~h}(46.5 \%)\end{array}$ & $\begin{array}{l}\text { From } 1 \mathrm{~h} \text { to less } \\
\text { than } 2 \mathrm{~h}(34 \%)\end{array}$ & $\begin{array}{l}\text { From } 1 \mathrm{~h} \text { to less than } 2 \mathrm{~h} \\
(39.2 \%)\end{array}$ \\
\hline $\begin{array}{l}\text { Most common } \\
\text { attack time }\end{array}$ & Nocturnally (73\%) & - & Nocturnally & - & $\begin{array}{l}\text { Between } 12 \text { am } \\
\text { and } 3 \text { am }\end{array}$ & Nocturnally(47.7\%) & $\begin{array}{l}\text { Midnight (28\%), } \\
\text { afternoon (27\%) }\end{array}$ & $\begin{array}{l}\text { Between } 7 \mathrm{am} \text { and } 10 \mathrm{am} \text {, } \\
2 \mathrm{pm} \text { and } 4 \mathrm{pm}\end{array}$ \\
\hline Seasonal propensity & Spring and Autumn & - & Spring & - & $\begin{array}{l}\text { Oct., Sep., Apr., } \\
\text { Mar. and Nov. }\end{array}$ & - & Dec., Mar. & Spring \\
\hline
\end{tabular}

CH: cluster headache; $\mathrm{CCH}$ : chronic cluster headache; ECH: episodic cluster headache; $*$ : Peak age onset (36\%). 
Eastern and Western $\mathrm{CH}$ patients may be due to ethnic, social and/or cultural factors. We also found that $45.8 \%$ of headaches were aggravated by physical activities, a percentage higher than in Caucasian (21.7\%) [6] and Taiwanese (7\%) [14] patients, but similar to that of patients in Japan (31.0\%) [15].

The signature feature of $\mathrm{CH}$ is its rhythmicity, which uniquely displays both a circannual and circadian periodicity [2-4]. We have observed a seasonal propensity of $\mathrm{CH}$, with more attacks occurring in the spring and fewer during the summer than at other times of the year, a result consistent with previous findings $[5,7,13,14]$. The periodicity of $\mathrm{CH}$ suggests the involvement of the suprachiasmatic nucleus $(\mathrm{SCN})$ of the hypothalamus, the biological clock [26-31]. Marked seasonal variations have been observed in the volume, total cell number and number of vasopressin expressing cells of the human $\mathrm{SCN}$, with the SCN being smaller during the summer than during any other season of the year [32]. This may explain, at least in part, the lower prevalence of attack during the summer months in current study. We also found $\mathrm{CH}$ commonly occurred from 7 am to 10 am and from $2 \mathrm{pm}$ to $4 \mathrm{pm}$ compared to other time. However, we didn't demonstrate most of the headache attacks occurred nocturnally as previous reports $[5,7,13,15]$. This discrepancy in circadian rhythmicity of $\mathrm{CH}$ attacks might be due to insignificant diurnal variations in the volume or vasopressin cell number of the human SCN in contrast with the annual cycle of the SCN [32].

Recent results from the United States Cluster Headache survey have revealed the differences between female and male $\mathrm{CH}$ including age of onset, family history, comorbid conditions, aura symptoms, pain locations and associated symptoms [33]. The data supported a previous study from a tertiary headache centre, which found some different characteristics in women with $\mathrm{CH}$ [22]. However, the current study showed no statistically significant difference in any of the clinical characteristics between male and female patient. The small sample size of our female patient population may result in such limit.

In the study we applied World Health Organization Quality of Life-8 (WHOQoL-8) to evaluate the quality of life in $\mathrm{CH}$ patients. This rating scale has also been widely used in a nationwide population-based headache survey in the mainland of China [16]. It seems that the scores of 8 items in $\mathrm{CH}$ patients were significantly lower than the data in migraineurs from above-mentioned survey. This may indicated $\mathrm{CH}$ had a more negative impact on quality of life than migraine.

Only $10.8 \%$ of our patients had previously been diagnosed with $\mathrm{CH}$, a lower percentage than in other Asian countries, including Japan (14\%). It took 10 years or even longer to receive a correct diagnosis for most of the $\mathrm{CH}$ patients in the study. These findings suggest that $\mathrm{CH}$ often remains unrecognized or misdiagnosed in China and that physicians may be unaware of this condition. Educating physicians about this recognizable and treatable condition and its diagnosis should be addressed.

This study had several limitations. Firstly, the clinical features were collected retrospectively and that this may result in a recall bias as compared to a prospective data collection with diaries. However, $\mathrm{CH}$ is a severe and excruciating headache disorder and thus the majority of the patients were easily to recall the clinical information about attacks. These may reduce the bias during interview. Moreover, the study has a relatively small number of $\mathrm{CH}$ patients, especially for female suffers. Lastly, patients were enrolled from a single headache clinic, although they came from 16 different regions in China.

\section{Conclusion}

In summary, this study is the first to describe the clinical characteristics of $\mathrm{CH}$ in Chinese patients based on a clinic sample. Most of the clinical characteristic of these patients were consistent with results in other Asian and in Western patients, including similar age at onset, male predominance, temporal or retro-orbital regions as common sites of pain, similar pain intensity of primary headaches, lacrimation as the most frequent autonomic symptom, high frequencies of migrainous features, low frequency of positive family history and seasonal propensity in spring and autumn. We found that several characteristics were similar to those of other Asian populations, but differed from results in Western patients, including the low percentage of patients with chronic $\mathrm{CH}$, pain sites mainly focused on areas distributed by the first division of the trigeminal nerve, the relative low frequency of restlessness and absent aura before headache attack. These may be due to different lifestyle, genetic, racial and cultural factors between Eastern and Western $\mathrm{CH}$ patients.

\section{Competing interests \\ The authors declared no conflict of interest.}

\section{Authors' contributions}

SY ZD conceived and designed the experiments. ZD HD WD MP ZL JL MZ ZZ RL performed the experiments. ZD SY analyzed the data and drafted the paper. All authors read and approved the final manuscript.

\section{Acknowledgement}

We thank Medjaden Bioscience Limited for assisting in the preparation of this manuscript. The funding support of the National Science Foundation Committee (NSFC) in China is gratefully acknowledged (no. 30970417 and no. 81171058)

Received: 17 December 2012 Accepted: 17 December 2012 Published: 21 March 2013

\section{References}

1. Headache Classification Subcommittee of the International Headache Society (2004) The International Classification of Headache Disorders: 2nd edition. Cephalalgia 24(Suppl 1):60-63

2. May A (2005) Cluster headache: pathogenesis, diagnosis, and management. Lancet 366:843-855 
3. Nesbitt AD, Goadsby PJ (2012) Cluster headache. BMJ 344:e2407

4. Dodick DW, Rozen TD, Goadsby PJ, Silberstein SD (2000) Cluster headache. Cephalalgia 20:787-803

5. Bahra A, May A, Goadsby PJ (2002) Cluster headache: a prospective clinical study with diagnostic implications. Neurology 58:354-361

6. Schurks M, Kurth T, de Jesus J, Jonjic M, Rosskopf D, Diener HC (2006) Cluster headache: clinical presentation, lifestyle features, and medical treatment. Headache 46:1246-1254

7. Gaul C, Christmann N, Schröder D, Weber R, Shanib H, Diener HC, Holle D (2012) Differences in clinical characteristics and frequency of accompanying migraine features in episodic and chronic cluster headache. Cephalalgia 32:571-577

8. Sjaastad O, Bakketeig LS (2003) Cluster headache prevalence. Vaga study of headache epidemiology. Cephalalgia 23:528-533

9. Torelli P, Beghi E, Manzoni GC (2005) Cluster headache prevalence in the Italian general population. Neurology 64:469-474

10. Katsarava Z, Obermann M, Yoon MS, Dommes P, Kuznetsova J, Weimar C, Diener HC (2007) Prevalence of cluster headache in a population-based sample in Germany. Cephalalgia 27:1014-1019

11. Fischera M, Marziniak M, Gralow I, Evers S (2008) The incidence and prevalence of cluster headache: A meta-analysis of population-based studies. Cephalalgia 28:614-618

12. Broner SW, Cohen JM (2009) Epidemiology of cluster headache. Curr Pain Headache Rep 13:141-146

13. Rozen TD, Fishman RS (2012) Cluster headache in the United States of America: demographics, clinical characteristics, triggers, suicidality, and personal burden. Headache 52:99-113

14. Lin KH, Wang PJ, Fuh JL, Lu SR, Chung CT, Tsou HK, Wang SJ (2004) Cluster headache in the Taiwanese - A clinic-based study. Cephalalgia 24:631-638

15. Imai N, Yagi N, Kuroda R, Konishi T, Serizawa M, Kobari M (2011) Clinical profile of cluster headaches in Japan: Low prevalence of chronic cluster headache, and uncoupling of sense and behaviour of restlessness. Cephalalgia 31:628-633

16. Yu S, Liu R, Zhao G, Yang X, Qiao X, Feng J, Fang Y, Cao X, He M, Steiner T (2012) The prevalence and burden of primary headaches in China: a population-based door-to-door survey. Headache 52:582-591

17. Manzoni GC, Terzano MG, Moretti G, Cocchi M (1981) Clinical observations on 76 cluster headache cases. Eur Neurol 20:88-94

18. Ekbom K, Svensson DA, Traff H, Waldenlind E (2002) Age at onset and sex ratio in cluster headache: observations over three decades. Cephalalgia 22:94-100

19. Torelli P, Cologno D, Cademartiri C, Manzoni GC (2000) Possible predictive factors in the evolution from of episodic to chronic cluster headache. Headache 40:798-808

20. Manzoni GC (1997) Male preponderance of cluster headache is progressively decreasing over the years. Headache 37:588-589

21. Manzoni GC (1998) Gender ratio of cluster headache over the years: a possible role of changes in lifestyle. Cephalalgia 18:138-142

22. Rozen TD, Niknam RM, Shechter AL, Young WB, Silberstein SD (2001) Cluster headache in women: clinical characteristics and comparison with cluster headache in men. J Neurol Neurosurg Psychiatry 70:613-617

23. Donnet A, Lanteri-Minet M, Guegan-Massardier E, Mick G, Fabre N, Géraud G, Société Française d'Etude des Migraines et Céphalées (SFEMC) et al (2007) Chronic cluster headache: a French clinical descriptive study. J Neurol Neurosurg Psychiatry 78:1354-1358

24. Silberstein SD, Niknam R, Rozen TD, Young WB (2000) Cluster headache with aura. Neurology 54:219-221

25. Rozen TD (2011) Cluster headache with aura. Curr Pain Headache Rep 15:98-100

26. Pringsheim T (2002) Cluster headache: evidence for a disorder of circadian rhythm and hypothalamic function. Can J Neurol Sci 29:33-40

27. Kudrow L (1987) The cylic relationship of natural illumination to cluster period frequency. Cephalalgia 7:76-78

28. Strittmatter M, Hamann GF, Grauer M, Fischer C, Blaes F, Hoffmann KH, Schimrigk K (1996) Altered activity of the sympathetic nervous system and changes in the balance of hypophyseal, pituitary and adrenal hormones in patients with cluster headache. Neuroreport 7:1229-1234

29. Hofman MA, Zhou JN, Swaab DF (1996) Suprachiasmatic nucleus of the human brain: an immunocytochemical and morphometric analysis. Anat $\operatorname{Rec} 244: 552-562$
30. Holland PR, Goadsby PJ (2009) Cluster headache, hypothalamus, and orexin. Curr Pain Headache Rep 13:147-154

31. Holle D, Obermann M (2011) Cluster headache and the hypothalamus: causal relationship or epiphenomenon? Expert Rev Neurother 11:1255-1263

32. Hofman MA, Purba JS, Swaab DF (1993) Annual variations in the vasopressin neuron population of the human suprachiasmatic nucleus. Neuroscience 53:1103-1112

33. Rozen TD, Fishman RS (2012) Female cluster headache in the United States of America: what are the gender differences? Results from the United States Cluster Headache Survey. J Neurol Sci 317:17-28

doi:10.1186/1129-2377-14-27

Cite this article as: Dong et al: Clinical profile of cluster headaches in China - a clinic-based study. The Journal of Headache and Pain 2013 14:27.

\section{Submit your manuscript to a SpringerOpen ${ }^{\odot}$ journal and benefit from:}

- Convenient online submission

- Rigorous peer review

- Immediate publication on acceptance

- Open access: articles freely available online

- High visibility within the field

- Retaining the copyright to your article

Submit your next manuscript at $\gg$ springeropen.com 